\title{
Cross-Linked Aluminum Dioxybenzene Coating for Stabilization of Silicon Electrodes
}

Daniela Molina Piper, ${ }^{\mathrm{a}}$ Younghee Lee, ${ }^{\mathrm{b}}$ Seoung-Bum Son, ${ }^{\mathrm{c}}$ Tyler Evans, ${ }^{\mathrm{a}}$ Feng Lin, ${ }^{\mathrm{d}}$ Dennis Nordlund, ${ }^{\mathrm{e}}$ Xingcheng Xiao, ${ }^{\mathrm{f}}$ Steven M. George, ${ }^{\mathrm{a}, \mathrm{b}}$ Se-Hee Lee, ${ }^{\mathrm{a},} *$ and Chunmei Ban ${ }^{\mathrm{c},} *$

${ }^{a}$ Department of Mechanical Engineering

University of Colorado at Boulder, Boulder, CO, 80309 (USA)

${ }^{\mathrm{b}}$ Department of Chemistry and Biochemistry

University of Colorado at Boulder, Boulder, CO, 80309 (USA)

${ }^{\mathrm{c}}$ Center for Chemistry and Nanoscience, National Renewable Energy Laboratory, Golden, $\mathrm{CO}, 80401$ (USA)

${ }^{\mathrm{d}}$ Lawrence Berkeley National Laboratory, Berkeley, CA, 94720 (USA)

${ }^{\text {e }}$ Stanford Synchrotron Radiation Lightsource, SLAC National Accelerator Laboratory, Menlo Park, CA, 94025 (USA)

${ }^{\mathrm{f}}$ General Motors Global Research and Development Center, Warren, MI, 48090 (USA)

* Corresponding authors: Dr. Chunmei Ban (chunmei.ban@nrel.gov), Prof. Se-Hee Lee (sehee.lee@colorado.edu) 


\begin{abstract}
Progress toward a commercially viable silicon anode for lithium-ion batteries has been impeded by silicon's rapid capacity fade caused by large volumetric expansion and unstable solid-electrolyte interphases. This study focuses on developing unique coating chemistries to stabilize the surface of silicon ( $\mathrm{Si}$ ) electrodes via molecular layer deposition (MLD), as well as to accommodate volume changes during electrochemical reactions. A new reaction precursor - an aromatic organic diol, hydroquinone — combined with trimethylaluminum, has led to a robust, elastic, conductive surface coating composed of aluminum dioxybenzene. We studied the chemical and physical properties of this surface coating using X-ray absorption spectroscopy, electrochemical impedance, and nanoindentation. The flexibility of the coating enables the accommodation of volumetric changes and maintenance of the mechanical integrity of the Si electrodes. By applying this robust and conductive trimethylaluminumhydroquinone coating, we demonstrate a Si anode that is reversible and capable of high performance and high rate, achieving over 200 cycles with capacities of nearly $1500 \mathrm{mAh} \mathrm{g}^{-1}$. This research elucidates the significance of surface modification for high-energy battery materials with large volume changes, and also provides a platform for a new design of electrode surface coatings, with the aim of achieving durable, high-energy-density lithium-ion batteries.
\end{abstract}

Keywords: surface modification; molecular layer deposition; silicon; and lithium ion batteries. 


\section{Introduction}

The power market is experiencing rapid growth in demand for advanced lithium-ion batteries (LIBs) capable of enabling high-power and high-energy applications, such as electric vehicles. This demand is driving research to find new materials and chemistries that will meet the performance requirements of high energy density, high rate capability, and long lifetime [1-3]. Increasing the energy density of LIBs requires developing electrode materials with higher charge capacity or higher cell voltage [4-8], and improving rate capability and cycle life involves stabilizing the active materials and solid-electrolyte interphase (SEI). In the search for such materials, silicon has emerged as the most attractive high-energy anode material due to its low working voltage and high theoretical specific capacity of $3579 \mathrm{mAh} \mathrm{g}^{-1}$, nearly a 10-fold increase relative to state-of-the-art graphite anodes [9-14]. The Si anode has realized substantial gains in specific and volumetric capacity, but critical challenges prevent its commercialization. These challenges are associated with volume expansion-up to 27 times more volume change in Si's alloying mechanism than that observed during graphite's intercalation reaction with $\mathrm{Li}(\sim 10 \%-13 \%)$ [15-17]. Such severe volumetric change generates structural degradation and instabilities of the SEI layer [14,18]. Ultimately, these deficiencies result in low coulombic efficiencies (CE), rapid capacity degradation, and short battery life.

Degradation of the Si active material itself has been mitigated by incorporating materials smaller than $150 \mathrm{~nm}$ [19]. However, degradation of the entire electrode network due to the $\sim 300 \%$ volume change of the nano-Si particles [20] has yet to be solved practically. Factors that are detrimental to the structural integrity of the electrodes include broken conductive pathways, active material isolation, active material agglomeration, and continuous formation of an SEI layer. Ultimately, these factors are fatal to the electrochemical performance of any Si-based anode [20,21].

Nanostructured architectures to mitigate the volumetric changes have been explored, 
including using complex hierarchical structure with the assistance of carbon-based supporting materials [22-25]. However, large-scale fabrication poses a significant hurdle for many practical applications. Surface modifications, which can chemically modify the surface of silicon via the covalent binding of nucleophilic substrates ( $\mathrm{Si}-\mathrm{OH})$, are a unique and scalable approach to address both the unstable surface chemistry and the mechanical integrity. Atomic layer deposition (ALD) of aluminum oxide has been used to produce conformal surface coatings for layered metal-oxide cathode materials [26]. Unlike cathode materials, Si particles are covered by an insulating and rigid oxide layer, and also suffer from the morphological and volumetric changes during Li cycling. Therefore, in addition to the requirement for chemical stability, a functional coating with the control of thickness and mechanical properties is required.

MLD was introduced to produce the hybrid inorganic-organic coating composed of aluminum oxide and glycerol. The hybrid coating has been shown to be effective in obtaining reversible cycling in a silicon electrode [27]. This present work takes advantage of this approach and develops a new polymeric coating material for silicon electrodes by employing reaction precursors such as trimethylaluminum (TMA) and an aromatic organic diol, hydroquinone (HQ). The coating integrates aluminum oxides into a cross-linked dioxybenzene matrix, resulting in products containing electronically conductive bonding environments. By applying this new hybrid coating on conventional Si electrodes, it enables sustainable cycling with capacities of nearly $1500 \mathrm{mAh} \mathrm{g}^{-1}$ after 100 cycles and CEs in excess of 99\%. Diagnostic techniques including X-ray absorption spectroscopy, electrochemical impedance, and nanoindentation have been performed to reveal chemical and physical properties of the hybrid coating and its effects on the electrochemical performance of the $\mathrm{Si}$ anodes. The MLD-enabled chemistry overcomes many impediments in wet-chemistry fabrication for surface modification and also greatly extends the compositional possibilities of 
surface modifiers on LIB electrodes.

\section{Materials and Methods}

\subsection{Molecular Layer Deposition}

AlHQ films were grown directly on the nano-Si composite electrodes using a viscous hot-wall reactor (see Fig. 1 for detailed chemistry) [28]. The AlHQ reaction sequence was: i) dose trimethylaluminum for $1 \mathrm{~s}$; ii) hold trimethylaluminum pressure static for $30 \mathrm{~s}$; iii) evacuate for $60 \mathrm{~s}$; iv) flow $50 \mathrm{sccm}$ of $\mathrm{N}_{2}$ purge for $600 \mathrm{~s}$; v) evacuate for $60 \mathrm{~s}$; vi) dose hydroquinone for $1 \mathrm{~s}$; vii) hold hydroquinone pressure static for $30 \mathrm{~s}$; viii) evacuate for $60 \mathrm{~s}$; ix) flow 50 $\mathrm{sccm}$ of $\mathrm{N}_{2}$ purge for $600 \mathrm{~s}$; and $\mathrm{x}$ ) evacuate for $60 \mathrm{~s}$. This sequence constitutes one MLD cycle of AlHQ. The typical growth rate for the AlHQ chemistry is $7.5 \AA$ per cycle. The electrodes were coated with five cycles of AlHQ and the reaction was conducted at $150^{\circ} \mathrm{C}$. Post-deposition heat treatments were conducted under argon in a tube furnace at $200^{\circ} \mathrm{C}$ for 12 h. The post-deposition heat treatments conducted in air at $150^{\circ} \mathrm{C}$ were done in a box furnace for $12 \mathrm{~h}$.

\subsection{Material Preparation}

The nano-Si-based composite electrodes were prepared by spreading nano-Si powder $(50 \mathrm{~nm}$, Alpha Aesar), acetylene black (AB), and PVDF (polyvinylidene fluoride, binder) mixed in $\mathrm{N}$ methyl pyrolidinone solvent (60:20:20 weight ratio) on a piece of $\mathrm{Cu}$ foil. Once the electrodes were dried and calendared, some were treated with AlHQ coating. Before assembling the cells, the 0.5 -inch punched electrodes were dried overnight $\left(120^{\circ} \mathrm{C}\right)$ in a vacuum oven.

\subsection{Electrochemical Measurement}

Electrochemical measurements were carried out using an Arbin $^{\mathrm{TM}} 2000$ battery test station. All cells were assembled in an Ar-filled glove box using the prepared nano-Si/bare and nano$\mathrm{Si} / \mathrm{AlHQ}$ electrodes as the working electrodes and lithium metal foil as the counter electrode. 
The electrolyte was $1 \mathrm{M} \mathrm{LiPF}_{6}$ dissolved in a 1:1 (volume ratio) mixture of ethylene carbonate (EC) and diethyl carbonate (DEC); the separator was a glass micro-fiber disk (Whatman ${ }^{\mathrm{TM}}$ GF/F) and the shell was a stainless steel CR2032 coin cell (VWR Inter.). We used a constant current, constant voltage $(\mathrm{CCCV})$ testing scheme to cycle the cells at room temperature. The cells were discharged (lithiated) and charged (delithiated) with various cycling currents between 0.05 and $1 \mathrm{~V}\left(\mathrm{vs} . \mathrm{Li} / \mathrm{Li}^{+}\right)$. The conducted rate study was carried out with charging rates ranging from $\mathrm{C} / 20$ to $10 \mathrm{C}$. The discharge rates were started at $\mathrm{C} / 20$, increased to $\mathrm{C} / 10$, and maintained at this rate for subsequent cycling. Charging was conducted with constant current (CC) and discharge was conducted with CCCV cycling parameters. Electrochemical measurements were all normalized based on the mass of nano-Si in each electrode (typically $0.5-0.8 \mathrm{mg} \mathrm{cm}^{-2}$ and the weight ratio of Si:PVDF:AB is $\left.6: 2: 2\right)$.

\subsection{Material Characterization}

X-ray absorption spectroscopy (XAS) measurements were performed on the bending magnet beamline 8-2 at Stanford Synchrotron Radiation Lightsource (SSRL) using a ring current of $500 \mathrm{~mA}$ and a $11001 \cdot \mathrm{mm}^{-1}$ spherical grating monochromator with $20-\mu \mathrm{m}$ entrance and exit slits, providing $\sim 0.5 \times 10^{10} \mathrm{ph} \cdot \mathrm{s}^{-1}$ at $0.2-\mathrm{eV}$ resolution in a $1-\mathrm{mm}^{2}$ beam spot. Data were acquired under ultrahigh vacuum $\left(10^{-9}\right.$ torr $)$ in a single load at room temperature using total electron yield (TEY), where the sample drain current was collected. All spectra were normalized by the current from a gold-evaporated fine grid positioned upstream of the main chamber. XAS samples were mounted on an aluminum sample holder with double-sided carbon tape in a helium-filled glove box, and they were transferred to the load-lock chamber in a double-contained container, using a glove bag purged with argon for the transfer. The microstructure of AlHQ on the nano-Si particles was investigated by an analytical transmission electron microscope (TEM) (TECNAI F20) operating at $200 \mathrm{keV}$.

\section{Results and Discussion}


Alumination of hydroquinone in liquid was studied to produce polydentate Lewis acids for strong binding with nucleophilic substrates [29]. The knowledge has been successfully transferred here to a produce cross-linked aluminum dioxybenzene compound via MLD.

The hybrid coating (denoted by AlHQ) was deposited conformally onto the nano-Si anodes using the sequential, self-limiting reaction of TMA $\left(\mathrm{Al}\left(\mathrm{CH}_{3}\right)_{3}\right)$ and $\mathrm{HQ}\left(\mathrm{C}_{6} \mathrm{H}_{4}(\mathrm{OH})_{2}\right)$ according to:

(A) $\mathrm{Si}-\mathrm{OH}^{*}+\mathrm{Al}\left(\mathrm{CH}_{3}\right)_{3} \rightarrow \mathrm{Si}-\mathrm{O}-\mathrm{Al}\left(\mathrm{CH}_{3}\right)_{2} *+\mathrm{CH}_{4}$

(B) $\mathrm{Si}-\mathrm{O}-\mathrm{Al}\left(\mathrm{CH}_{3}\right)_{2} *+\mathrm{HOC}_{6} \mathrm{H}_{4} \mathrm{OH} \rightarrow \mathrm{Si}-\mathrm{O}-\mathrm{Al}-\mathrm{OC}_{6} \mathrm{H}_{4} \mathrm{OH}^{*}+\mathrm{CH}_{4}$

where asterisks indicate surface species and Si represents the underlying Si electrode. Figure 1a shows a schematic of the controlled layered structure of the AlHQ used in this work. The growth rate of this MLD reaction is measured to be $7.5 \AA$ per AB cycle at a substrate temperature of $150^{\circ} \mathrm{C}$.

As illustrated in Fig. 1a, the laminated electrode was used as a substrate for the hybrid coating. Based on the similar mechanism of ALD, the MLD method allows for self-limiting, sequential vapor reactions that are able to reach the electrode's porous structure and covalently bind to available surfaces. This enhances a strong, flexible network within the electrode that binds the materials and ensures sufficient contact area throughout cycling. During the MLD reaction, the aluminum oxide was connected with dioxybenzene via a conjugated chain in the form of (Al-O-benzene-O-Al- $)_{n}[30,31]$. Further dehydrogenation occurs when annealing the as-deposited film under both inert and air atmosphere, as shown in Fig. 1b. Dehydrogenation induces a longitudinal crosslinking reaction of the aluminumdioxybenzene chains [32]. The three-dimensional cross-linked structure leads to improved conductive and mechanical properties, as discussed in a later section. Furthermore, the 
crosslinking structure enabled by the polydentate Lewis acid not only creates a strong covalent bonding to the surface of silicon particles, but also provides chemical stability of the coating film [31].

The effect of the crosslinking reaction on the thickness and density of the MLD film has been evaluated and summarized in Fig. S1. Results confirm the densification of the AlHQ coating associated with the longitudinal crosslinking of aluminum-dioxybenzene chains. In addition to improving the film's conductive properties, such crosslinking was also expected to improve the mechanical properties of the AlHQ coating. To study the mechanical effects of heat treatment, we focused our attention on 100-nm-thick AlHQ coatings on silicon wafers. The heat treatments were all conducted in air, after the deposition process, for a span of $12 \mathrm{~h}$. Nanoindentation was used to study the ratio of hardness to Young's modulus $\left(H / E^{*}\right)$, which allows determination of the film's wear resistance as a function of temperature. Results reveal the highest $H / E^{*}$ for the AlHQ coating heat-treated at $150^{\circ} \mathrm{C}$, suggesting a more elastic than plastic deformation under contact [33], with negative returns at $200^{\circ} \mathrm{C}$ (Table 1). Materials with higher $H / E^{*}$ are expected to have smaller accumulative strains and strain energies; therefore, expected to have better wear resistances which are the indications of the durability of materials under severe mechanical loading [33]. Additionally, the much lower Young's modulus than ALD ceramic coatings $\left(34.9 \mathrm{GPa}\right.$, compared to $170 \mathrm{GPa}$ for $\mathrm{ALD} \mathrm{Al}_{2} \mathrm{O}_{3}$ ) makes it much more flexible and able to accommodate the volume expansion and contraction of $\mathrm{Si}$ nanoparticles [34]. The cross-linked AlHQ coatings show improved mechanical properties that ensure the structural integrity of the nanocomposite electrodes. The crosslinking reaction induced by dehydrogenation (illustrated in Fig. 1b) also occurs under inert atmosphere. Thus, an analogous enhancement effect in the mechanical and structural stability is expected in the AlHQ coating annealed under argon (Ar) atmosphere.

The improvements in mechanical and structural properties are attributed to the changes 
in chemical environments of the ultra-thin, MLD-coated protection layer upon thermal annealing. As a powerful characterization tool to study local chemical environments with site specificity and surface sensitivity [35-37], soft XAS was used here to monitor O K-edge spectra of 100 -nm-thick AlHQ films treated at $25^{\circ} \mathrm{C}, 100^{\circ} \mathrm{C}, 200^{\circ} \mathrm{C}, 350^{\circ} \mathrm{C}$, and $500^{\circ} \mathrm{C}$ under both air and Ar environments. Given the high sensitivity of this method, the crosslinking process in the AlHQ coating and its conversion to $\mathrm{Al}_{2} \mathrm{O}_{3}$ after pyrolysis can be monitored by tracking the oxygen bonding environments in the XAS spectra. By watching the spectroscopic fingerprint as a function of temperature and atmosphere, we are able to determine the optimal annealing condition for the MLD layer under an Ar environment. Figure 2 shows the O Kedge XAS spectra for the samples annealed under Ar atmosphere (the spectra for the samples annealed under air atmosphere are shown in Fig. S2). We note that overall, the O K-edge XAS spectra resemble that of aluminum oxyhydrides $(\mathrm{AlO}(\mathrm{OH}))$, with slightly broader features than that of gibbsite $\left(\mathrm{Al}(\mathrm{OH})_{3}\right)$, as depicted in Fig. 2. This indicates that the asprepared AlHQ-MLD film has a similar electronic structure to both Al-O- and Al-OH functionalities in $\mathrm{AlO}(\mathrm{OH})$. Apart from the $\sigma$ resonance around $540 \mathrm{eV}$ (associated with the single oxygen bond in Al-O- and Al-O-C, as well as C-O-), there is a relatively well-defined shape resonance near $560 \mathrm{eV}$ in the as-prepared MLD film; this shape resonance closely matches that found for the Al-O- bond in $\mathrm{AlO}(\mathrm{OH})[38,39]$. The AlHQ coating was synthesized from the reaction between TMA and HQ, as summarized in reactions A and B. However, the signature of the terminal $-\mathrm{OH}$ group from hydroquinone (at about $535 \mathrm{eV}$ ) is greatly suppressed in the AlHQ film. The quenched peak confirms the self-limited and sequential reaction between the $-\mathrm{OH}$ in $\mathrm{HQ}$ and TMA, which is consistent with previous results [40]. We also notice a low-energy peak around $533 \mathrm{eV}$ that cannot be associated with the saturated bond of the AlHQ framework depicted in Fig. 1b. Based on careful alignment with the core-excitation database of Hitchcock and co-workers, the resonance lines up with carbonate functionalities [41]. Based on the established reaction pathway of carbonates on an 
oxygen-covered surface, we speculate that during the processing of the AlHQ film, residual $\mathrm{CO}_{2}$ reacts with the surface oxide to form carbonates [42,43]. As shown in Fig. 2 and Fig. 2S, the peak (around $533 \mathrm{eV}$ ) undergoes gradual decomposition as the annealing temperature rises, indicating that the carbonate species are decomposed at high temperatures.

In regard to the chemistry evolution of the AlHQ coating upon post-deposition heat treatments, we used two energy spans of the O K-edge XAS spectra (535-540 eV, upward arrow, and 542-548 eV, downward arrow) to track the transition of $\mathrm{AlHQ}$ to $\mathrm{Al}_{2} \mathrm{O}_{3}$ as a function of annealing temperature. When the annealing temperature is above $200^{\circ} \mathrm{C}$, we clearly observed the changes of electronic structure toward $\mathrm{Al}_{2} \mathrm{O}_{3}$ for the samples heat treated in both air and $\mathrm{Ar}$ environments. The conversion to $\mathrm{Al}_{2} \mathrm{O}_{3}$ following pyrolysis is obvious at $350^{\circ} \mathrm{C}$. However, a slower transition was observed when using Ar in comparison to the airannealed sample. The oxygen deficiency in an Ar environment limits oxygen functionalization, resulting in slower kinetics for the crosslinking reaction and the following pyrolysis. Based on these observations, we determined to use a higher temperature, $200^{\circ} \mathrm{C}$, for Ar annealing to induce crosslinking reactions in AlHQ coating with no electronic structure changes toward $\mathrm{Al}_{2} \mathrm{O}_{3}$.

Electrochemical impedance spectroscopy (EIS) was used to evaluate the effect of coating and post-annealing conditions on the ohmic resistances of the electrodes, as summarized in Fig. S3a. The ohmic resistance of the uncoated Si electrode was $2.9 \Omega$, whereas that of the as-deposited AlHQ-coated Si electrode was $4.2 \Omega$. The as-deposited aluminum-dioxybenzene film is intrinsically insulating. After annealing, the coated $\mathrm{Si}$ electrodes show reduced ohmic resistance: $4.0 \Omega$ for the air-treated electrode $\left(150^{\circ} \mathrm{C}\right)$ and 3.2 $\Omega$ for the Ar-treated electrode $\left(200^{\circ} \mathrm{C}\right)$. The crosslinking reaction under both heating conditions creates the cross-linked aromatic backbone that can improve the conductivity given the conduction bands formed by their $\pi$ and $\pi^{*}$ orbitals $[31,44]$. However, the heating 
procedure under air causes oxidation of the $\mathrm{Cu}$ current collector and other electrode components [45-47], resulting in a more intrinsically resistive film than that one annealed under Ar. Therefore, the coated Si electrodes annealed under $\mathrm{Ar}$ at $200^{\circ} \mathrm{C}$ were used to determine the coating thickness and effect of coating on the electrochemical properties for $\mathrm{Si}$ anodes.

As described in the experimental section, five cycles of MLD were used to coat the Si electrode. In theory, the thickness of the as-deposited coating should be about $3.75 \mathrm{~nm}$ based on the growth rate of $7.5 \AA$ per cycle. After post-annealing, the thickness will be reduced along with the increase in density, as discussed in Fig. S1. The thickness of the annealed coating was confirmed by using high-resolution TEM. Figure 3 presents TEM images of the coated Si electrode after annealing. We observe a thin coating on the Si particles with a thickness of $\sim 3 \mathrm{~nm}$ (Fig. 3a-c). Moreover, we confirm the conservation of an intimate adherence and conformity of the AlHQ surface coating on the Si nanoparticles after postdeposition heat treatment at $200^{\circ} \mathrm{C}$ in Ar. TEM images show that the coating layer is a thin, dense, and conformal coating adhering to the nanoscale Si particles, despite it being an electrode surface-deposition process. The morphology indicates that using static dosing of the MLD precursors enables conformal coating of the nano-Si particles in the core of the porous electrode.

Most significantly, the MLD AlHQ coating has improved the cycling performance of the conventional Si-based electrodes, as shown in Fig. 4a. The Si anodes were prepared by using PVDF as a binder and $\mathrm{AB}$ as conductive additive, as described in the experimental section. Previous work has confirmed that PVDF fails to accommodate the volumetric changes in Si electrodes. Thus, PVDF has been selected as a binder for this work to distinctly distinguish the effects the AlHQ coating has on the mechanical integrity and electrochemical performance of Si anodes. Both electrodes with the as-deposited AlHQ coating and the cross- 
linked AlHQ coating (treated under Ar) were electrochemically tested at a rate of C/20 (175 $\left.\mathrm{mA} \mathrm{g}^{-1}\right)$ for the first five cycles and then at a rate of $\mathrm{C} / 10\left(350 \mathrm{~mA} \mathrm{~g}^{-1}\right)$ for all subsequent cycles. At cycle 200, the AlHQ-coated electrode exhibits a specific charge capacity of nearly $1500 \mathrm{mAh} \mathrm{g}^{-1}$ and CE values in excess of $99 \%$, whereas the as-deposited AlHQ-coated electrode achieves a stable capacity of about $1000 \mathrm{mAh} \mathrm{g}^{-1}$. (All the capacities were normalized based on total Si active material in each electrode.) The specific charge capacity of $1500 \mathrm{mAh} \mathrm{g}^{-1}$ of the coated $\mathrm{Si}$ anode corresponds to an electrode areal capacity of 0.581 $\mathrm{mAh} \mathrm{cm}^{-2}$ and a volumetric capacity of $1020 \mathrm{mAh} \mathrm{cm}^{-3}$ (considering an initial electrode thickness of about $5.7 \mu \mathrm{m}$ ). The improvements exhibited by the Si electrode coated with Artreated AlHQ, as compared to the non-heat-treated AlHQ coating are clear. However, both of these electrochemical performances significantly outperform the rapid degradation of an uncoated Si electrode, which fails by its $30^{\text {th }}$ cycle [27]. Moreover, the capacity retention of the Ar-treated AlHQ-coated electrode at 200 cycles nearly triples that of previous attempts to use MLD aluminum-glycerol coatings on Si electrodes [27]. As elaborated above, the crosslinking reaction in AlHQ coating occurs under both inert and air atmosphere. Therefore, improvements are also observed in the Si electrode coated with air-treated AlHQ, as indicated in Fig. S3b. The slightly low capacity in the Si electrode coated with air-treated AlHQ was attributed to the adverse effects air annealing has on the $\mathrm{Cu}$ current collector and other electrode components, as discussed earlier. Overall, such good cycle life and CEs are evidence that the AlHQ coating provides favorable mechanical properties and structural stability. These properties accommodate the volumetric changes of the nano-Si particles and preserve the structural integrity of the conventional electrode network throughout cycling.

In addition to providing structural integrity of the Si-based electrodes, the AlHQ-MLD surface coating also provides an improved electrode-electrolyte interface, consistent to our previous work with AlGL surface modification chemistries [27]. The first-cycle CEs of $84 \%$ 
and $86 \%$ for the as-deposited AlHQ-coated electrode and the AlHQ-coated electrode (treated under Ar), respectively, are evidence of the coating's ability to passivate those massive irreversible charge losses that occur at the initiation of the cell's cycling progressiontypically yielding a first-cycle CE less than $70 \%$ for conventional Si electrodes (PVDF used as the polymer binder) [27]. Based on the mechanical properties discussed in the previous section, we postulate that this highly cross-linked and robust polymeric framework, with a remarkable adherence to the native oxide surface of our Si nanoparticles, can expand upon lithiation and contract upon delithiation, preventing drastic changes to the coating and maintaining the electrode's structural integrity for hundreds of cycles [48]. What makes the AlHQ-MLD chemistry exceptional is the ability to promote conduction throughout its aromatic framework, especially after post-deposition heat treatment in Ar.

In lieu of a direct electrical conductivity measurement, we conducted an electrochemical rate test to study the transport properties of the Ar-treated AlHQ coating (Fig. 4b). At a rate of $5 \mathrm{C}\left(17.5 \mathrm{~A} \mathrm{~g}^{-1}\right)$, the AlHQ-coated electrode exhibited an average specific charge capacity of $1798 \mathrm{mAh} \mathrm{g}^{-1}$ - more than $750 \mathrm{mAh} \mathrm{g}^{-1}$ the capacity of our previous AlGL surface coating [27]. Also, at a rate of 10C (35 A g $\left.\mathrm{g}^{-1}\right)$, the AlHQ-coated electrode is still able to deliver specific charge capacities of about $1500 \mathrm{mAh} \mathrm{g}^{-1}$. Returning then to a rate of $\mathrm{C} / 2$ $\left(1.75 \mathrm{~A} \mathrm{~g} \mathrm{~g}^{-1}\right)$, the electrode recovered $91 \%$ of its specific charge capacity. This result attests to the maintenance of the electrode's structural integrity but also suggests that the cross-linked AlHQ coating provides very impressive ionic and electronic transport properties.

\section{Conclusion}

The favorable combination of mechanical and electrochemical properties achieved with AlHQ conformal coatings presents a major advancement in LIB technology. Surface modification had previously been deemed unsuitable for materials with large volume changes due to the mechanical failure of the coatings under large stresses. However, here, we have 
demonstrated the remarkable capability of the AlHQ coating, composed of aluminum dioxybenzene chains, to not only maintain a reversible Si-based anode structure with stable and high capacities for hundreds of cycles, but to also allow electron and ion exchange at very high rates. Dehydrogenation during low-temperature annealing of the AlHQ coating enhances the longitudinal crosslinking reaction of the aluminum-dioxybenzene chains, leads to improved mechanical strength and conductivity, and results in the remarkable performance shown in this work. This back-end (post-electrode manufacturing) surface modification process is also compatible with a range of Si-based electrode configurations. Moreover, this research may also be adaptable to a range of other high-capacity materials that represent an important advancement in high-energy LIBs applications. Future work will include an indepth study of this particular aromatic framework to fully understand its electrochemomechanics, in addition to improving the early-cycling CEs and initial capacity degradation through electrolyte modifications and/or prelithiation pretreatments.

\section{Acknowledgements}

The work at NREL was supported by the Assistant Secretary for Energy Efficiency and Renewable Energy, Office of Vehicle Technologies of the U.S. Department of Energy under Contract No. DE-AC02-05CH11231, Subcontract No. DE-AC-36-08GO28308 under the Batteries for Advanced Transportation Technologies (BATT) Program. The work at the University of Colorado at Boulder was funded by the U.S. Department of Energy under NREL subcontract number NFT-8-88527-01. The synthesis and materials characterization at CU Boulder were funded by a grant from the National Science Foundation (NSF), DMR1206462. The synchrotron X-ray portions of this research were carried out at the Stanford Synchrotron Radiation Lightsource, a Directorate of SLAC National Accelerator Laboratory and an Office of Science User Facility operated for the U.S. Department of Energy Office of Science by Stanford University. The authors would also like to acknowledge Dr. J.S. Lee and G. Kerr for technical support at SSRL Beam Line 8-2. 


\section{References}

[1] J.-M. Tarascon, Phil Trans. R. Soc. A 368 (2010) 3227-3241.

[2] J.-S. Lee, S.T. Kim, F. Cao, N.-S. Choi, M. Liu, K.T. Lee, J. Cho, Adv. Energy Mater. $1(2011)$ 203-211.

[3] T. Song, J. Xia, J.-H. Lee, D.H. Lee, M.-S. Kwon, J.-M. Choi, J. Wu, S.K. Doo, H.

Chang, Y. Huang, K.-C. Hwang, J.A. Rogers, U. Paik, Nano Lett. 10 (2010) 1710-1716.

[4] M. Armand, J.M. Tarascon, Nature 451 (2008) 652-657.

[5] J.B. Goodenough, Y. Kim, Chem. Mater. 22 (2009) 587-603.

[6] B. Kang, G. Ceder, Nature 458 (2009) 190-193.

[7] M.S. Whittingham, Chem. Rev. 104 (2004) 4271-4302.

[8] J.M. Tarascon, M. Armand, Nature 414 (2001) 359-367.

[9] J.O. Besenhard, J. Yang, M. Winter, J. Power Sources 68 (1997) 87-90.

[10] T.D. Hatchard, J.R. Dahn, J. Electrochem. Soc. 151 (2004) A838-A842.

[11] W.J. Weydanz, M. Wohlfahrt-Mehrens, R.A. Huggins, J. Power Sources 81 (1999) 237-242.

[12] X.-W. Zhang, P.K. Patil, C. Wang, A.J. Appleby, F.E. Little, D.L. Cocke, J. Power Sources 125 (2004) 206-213.

[13] L.Y. Beaulieu, T.D. Hatchard, A. Bonakdarpour, M.D. Fleischauer, J.R. Dahn, J. Electrochem. Soc. 150 (2003) A1457-1464.

[14] W.J. Zhang, J. Power Sources 196 (2011) 13-24. 
[15] Y. Koyama, T.E. Chin, U. Rhyner, R.K. Holman, S.R. Hall, Y.-M. Chiang, Adv. Funct. Mater. 16 (2006) 492-498.

[16] J.H. Lee, H.M. Lee, S. Ahn, J. Power Sources 113 (2003) 833-837.

[17] M. Winter, G.H. Wrodnigg, J.O. Besenhard, W. Biberacher, P. Novak, J. Electrochem. Soc. 147 (2000) 2427-2431.

[18] H. Wu, G. Chan, J.W. Choi, I. Ryu, Y. Yao, M.T. McDowell, S.W. Lee, A. Jackson, Y. Yang, L. Hu, Y. Cui, Nature Nanotech. 7 (2007) 310-315.

[19] X.H. Liu, L. Zhong, S. Huang, S.X. Mao, T. Zhu, J.Y. Huang, ACS Nano 6 (2011) $1522-1531$.

[20] R.A. Huggins, J. Power Sources 13 (1999) 81-82.

[21] H. Zhang, P.V. Braun, Nano Lett. 12 (2012) 2778-2783.

[22] H. Wu, Y. Cui, Nano Today 7 (2012) 414-429.

[23] M.-H. Park, M.G. Kim, J. Joo, K. Kim, J. Kim, S. Ahn, Y. Cui, J. Cho, Nano Lett. 9 (2009) 3844-3847.

[24] A. Magasinski, P. Dixon, B. Hertzberg, A. Kvit, J. Ayala, G. Yushin, Nature Mater. 9 (2010) 353-358.

[25] N. Liu, Z. Lu, J. Zhao, M.T. McDowell, H.-W. Lee, W. Zhao, Y. Cui, Nature Nanotech. 9 (2014) 187.

[26] Y.S. Jung, P. Lu, A.S. Cavanagh, C. Ban, G.H. Kim, S.H. Lee, S.M. George, S.J. Harris, A.C. Dillon, Adv. Energy Mater.3 (2012) 213-219.

[27] D. Molina Piper, J.J. Travis, M. Young, S.-B. Son, S.C. Kim, K.H. Oh, S.M. George, 
C. Ban, S.-H. Lee, Adv. Mater. 26 (2014) 1596-1601.

[28] Y.S. Jung, A.S. Cavanagh, A.C. Dillon, M.D. Groner, S.M. George, S.-H. Lee, J. Electrochem. Soc. 157 (2010) A75-A81.

[29] F.A.R. Kaul, M. Tschinkl, F.P. Gabbai, J. Organometalic Chem. 539 (1997) 187-191.

[30] B. Yoon, Y. Lee, D. Derk, C.B. Musgrave, S.M. George, ECS Trans. 33 (2011) 191195.

[31] Y. Lee and S.M. George, "Molecular Layer Deposition of Alucones and Zincones Using Hydroquinone", AVS 59 ${ }^{\mathrm{TH}}$ International Symposium \& Exhibition, Tampa, FL (Oct. 2012).

[32] J.W. DuMont, S.M. George, J. Phys. Chem. C 119(2015), 14603-14612.

[33] W. Ni, Y.-T. Cheng, M.J. Lukitsch, A.M. Weiner, L.C. Lev, D.S. Grummon, Appl. Phys. Lett. 85 (2004) 4028-4030.

[34] Q. Zhang, X. Xiao, Y.-T. Cheng, M.W. Verbrugg, Appl. Phys. Lett. 105 (2014) 061901.

[35] J. Stöhr, NEXAFS Spectroscopy, Springer-Verlag, Berlin, Germany 1992.

[36] F. Lin, I.M. Markus, D. Nordlund, T.-C. Weng, M.D. Asta, H.L. Xin, M.M. Doeff, Nat. Commun. 5 (2014) 3529.

[37] F. Lin, D. Nordlund, T.-C. Weng, Y. Zhu, C. Ban, R.M. Richards, H.L. Xin, Nature Commun. 5 (2014) 3358.

[38] Y.F. Hu, R.K. Xu, J.J. Dynes, R.I.R. Blyth, G. Yu, L.M. Kozak, P.M. Huang, Geochim. Cosmochim. Acta 72 (2008) 1959-1969. 
[39] R.K. Xu, Y.F. Hu, J.J. Dynes, A.Z. Zhao, R.I.R. Blyth, L.M. Kozak, P.M. Huang, Geochim. Cosmochim. Acta 74 (2010) 6422-6435.

[40] J.T. Francis, A.P. Hitchcock, J. Phys. Chem. 96 (1992) 6598-6610.

[41] A.P. Hitchcock, D.C. Mancini, J. Electron Spectrosc. Relat. Phenom. 67 (1994) 1-123.

[42] H.J. Freund, M.W. Roberts, Surf. Sci. Rep. 25 (1996) 225-273.

[43] A.F. Carley, D.E. Gallagher, M.W. Roberts, Surf. Sci. 183 (1987) L263-L268.

[44] C.K. Chiang, C.R. Fincher, Y.W. Park Jr., A.J. Heeger, H. Shirakawa, E.J. Louis, S.C. Gau, A.G. MacDiarmid, Phys. Rev. Lett. 39 (1977) 1098-1101.

[45] G. Eres, M. Regmi, C.M. Rouleau, J. Chen, I.N. Ivanov, A.A. Puretzky, D.B. Geohegan, ACS Nano 8 (2014) 5657-569.

[46] K. Chen, S. Song, D. Xue, Cryst. Eng. Comm. 15 (2013) 144-151.

[47] D.M. Piper, S.B. Son, J. J. Travis, Y. Lee, S. S. Han, S.C. Kim, K.H. Oh, S.M. George, S.H. Lee, C. Ban, J. Power Sources 275(2015) 605-611

[48] Y. He, D. Molina Piper, M. Gu, J.J. Travis, S.M. George, S.-H. Lee, A. Genc, L. Pullan, J. Liu, S.X. Mao, J.-G. Zhang, C. Ban, C. Wang, ACS Nano 8 (2014) 11816-11823. 


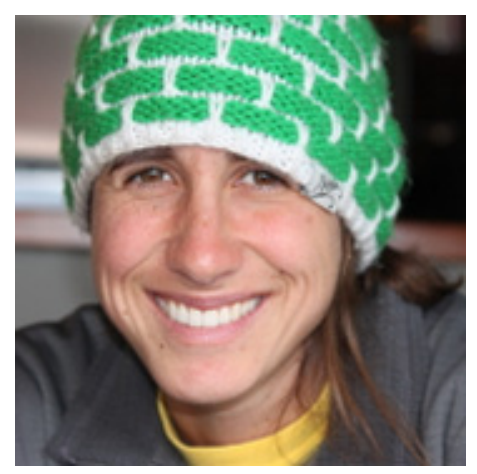

Daniela Molina Piper obtained her B.S. (2007) in Mechanical Engineering from Lehigh University, and M.S. (2012) and Ph.D. (2014) in Mechanical Engineering from the University of Colorado at Boulder (under Prof. Se-Hee Lee). Before pursuing her Ph.D., Dr. Molina Piper worked for Turner Construction Company and Totaí Citrus as a Project Engineer and Project Manager, respectively. She is currently working toward her postdoctoral research with Prof. Lee. Her research interest focuses on advanced materials for next-generation rechargeable lithium-ion batteries.

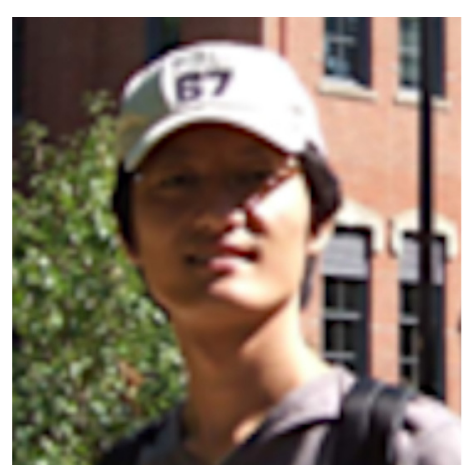

Younghee Lee obtained his B.S. (1999) in Chemistry and M.S. (2001) in Inorganic Chemistry from Seoul National University, and he is currently a Ph.D. candidate in the Department of Chemistry and Biochemistry at the University of Colorado at Boulder (under Prof. Steve M. George). Before pursuing his Ph.D., Mr. Lee worked for LG Chem as Senior Research Engineer. His research interest focuses on atomic and molecular layer deposition for energy applications. 


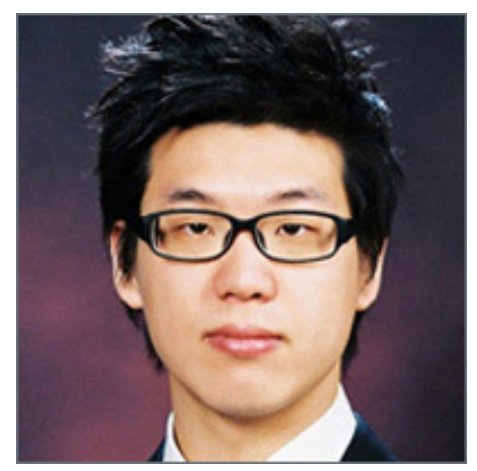

Seoung-Bum Son obtained his Ph.D. (2014) in Material Science and Engineering from Seoul National University (under Prof. Kyu H. Oh). Dr. Son joined the National Renewable Energy Laboratory in 2014 and has focused his research on developing new materials for energy storage and conversion. His general research interest is to improve the electrochemical properties of materials for Li ion batteries and controlling micro-structures and surface modifications of electrode materials.

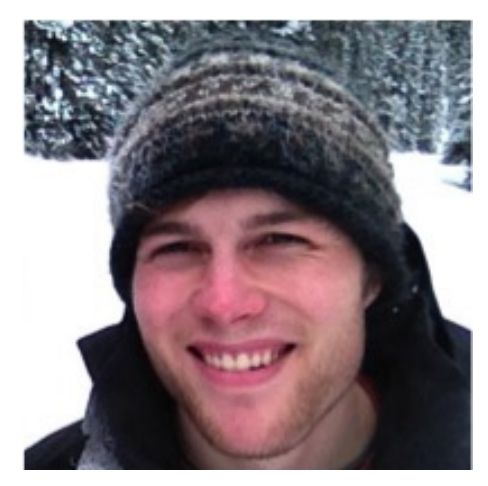

Tyler Evans obtained his B.S. (2012) in Environmental Sciences from the University of Notre Dame, and his M.S. (2014) in Mechanical Engineering from the University of Colorado at Boulder. He is currently a Ph.D. student in the Department of Mechanical Engineering at the University of Colorado at Boulder (under Prof. Se-Hee Lee). His doctoral research focuses on the facilitation of next-generation Li-ion electrode materials by utilizing room-temperature ionic liquid electrolytes.

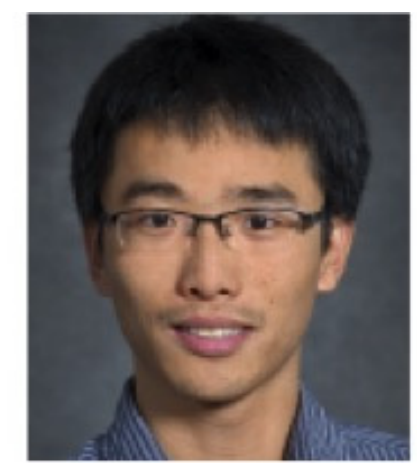

Feng Lin obtained his B.S. (2009) in Materials Science and Engineering from Tianjin University, and his Ph.D. (2012) in Material Science from the Colorado School of Mines. Dr. Ling joined Lawrence Berkeley National Laboratory in 2013 and has focused his research on 
developing new materials for renewable and environmental applications, and gaining a mechanistic understanding to enhance the possibilities for relevant technologies. His current research efforts include the design, synthesis, and electrochemical characterization of lithiumion battery materials and the understanding of electrochemical surface/interface using synchrotron X-ray and electron microscopy/spectroscopy techniques.

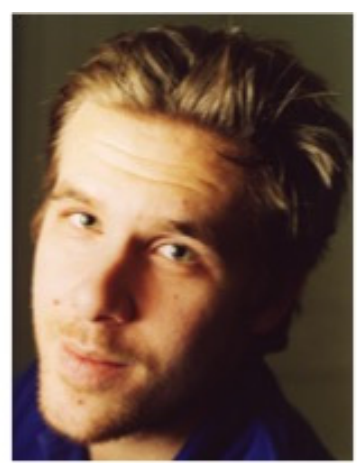

Dennis Nordlund obtained his Ph.D. (2004) in Chemical Physics from Stockholm University (under Anders Nilsson). Dr. Nordlund joined the SLAC National Accelerator Laboratory at Stanford University as a Postdoctoral Fellow. He currently holds a Staff Scientist position at the Stanford Synchrotron Radiation Lightsource with a research interest in graphene/graphite, catalysis, electrochemistry, H-bonded systems, electron localization, photovoltaics, surface chemistry, solid-state defects, X-ray instrumentation R\&D for synchrotrons, free-electron lasers and in-situ probing.

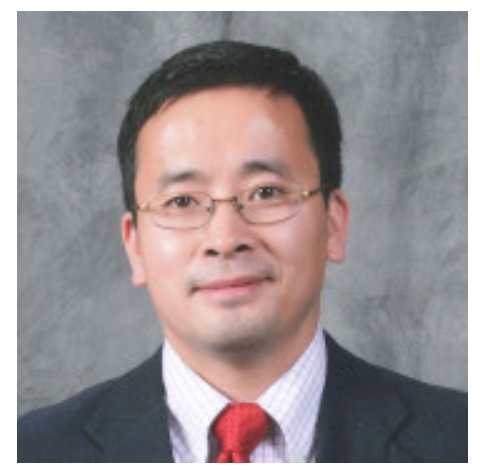

Xingcheng Xiao is a Staff Research Scientist at General Motors Global Research and Development Center. Dr. Xiao obtained his Ph.D. (2000) in Materials Science from Shanghai Institute of Ceramics, Chinese Academy of Sciences. He then worked as Alexander von Humboldt Fellow at Technical University of Munich, Germany, for one year. He was a research associate at Argonne National Laboratory from 2002-2005. He joined the GM R\&D center as a Senior Researcher in 2006 and was promoted to Staff Research Scientist in 2010. Dr. Xiao's research is focused on advanced nanostructured materials for electrochemical energy storage and surface sciences. 


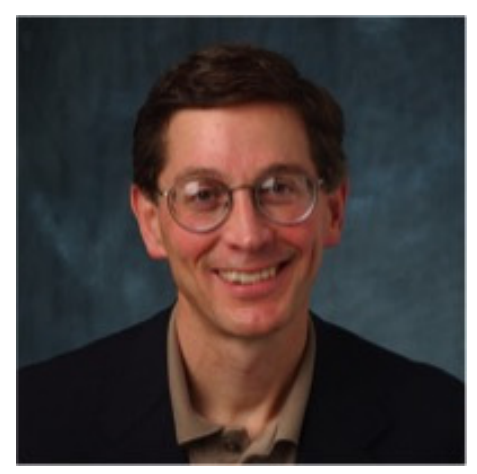

Steven M. George is a professor in the Department of Chemistry and Biochemistry at the University of Colorado at Boulder. He obtained his B.S. (1977) in Chemistry from Yale University and his Ph.D. (1983) in Chemistry from the University of California at Berkeley. He was a Bantrell Postdoctoral Fellow at Caltech prior to his appointment in the Department of Chemistry at Stanford University. He is an expert in atomic layer deposition (ALD) and is currently directing an internationally recognized research effort focusing on ALD. He is also a co-founder of ALD NanoSolutions, a startup company working to commercialize ALD technology.

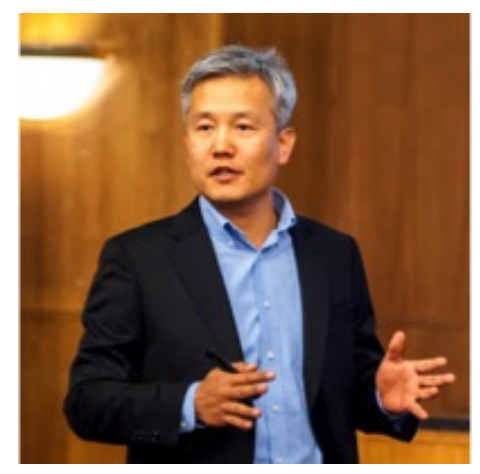

Se-Hee Lee is a professor in the Department of Mechanical Engineering at the University of Colorado at Boulder. He obtained his B.S. (1991), M.S. (1993), and Ph.D. (1997) in Material Science and Engineering from Seoul National University. He was a Postdoctoral Fellow and Senior Scientist at the National Renewable Energy Laboratory prior to his appointment at the University of Colorado at Boulder. He is an expert in electrochemistry and battery devices and has experience commercializing Li-ion technology as co-founder and Principal Scientist of Solid Power, a leader in the development of solid-state battery technology. 


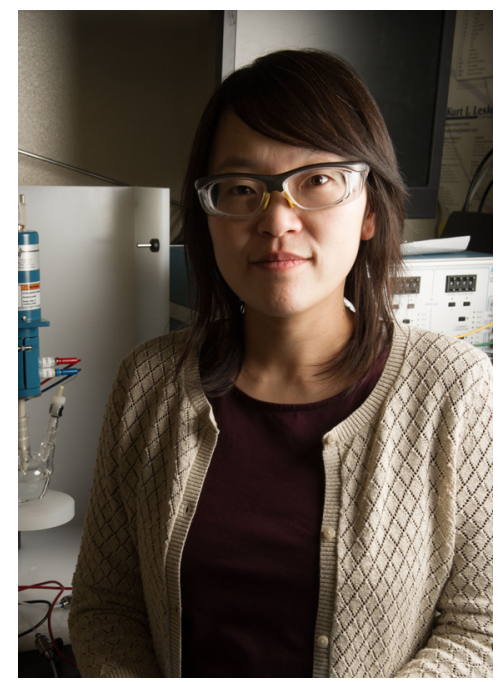

Chunmei Ban is a Scientist at National Renewable Energy Laboratory (NREL). She obtained her B.S. and M.S. (2003) in Electrochemistry from Tianjin University, and her Ph.D. (2008) in Chemistry from the State University of New York at Binghamton (under Prof. M. Stanley Whittingham). Dr. Ban joined NREL in 2008 and has focused her research on developing new materials for energy storage and conversion. Her current research efforts focus on synthesis and analysis of nanostructured materials with desirable structures and morphologies for nextgeneration energy storage, and surface modification of electrode materials with the aim of stabilizing the interface between electrode and electrolyte, for improved electrochemical properties. 


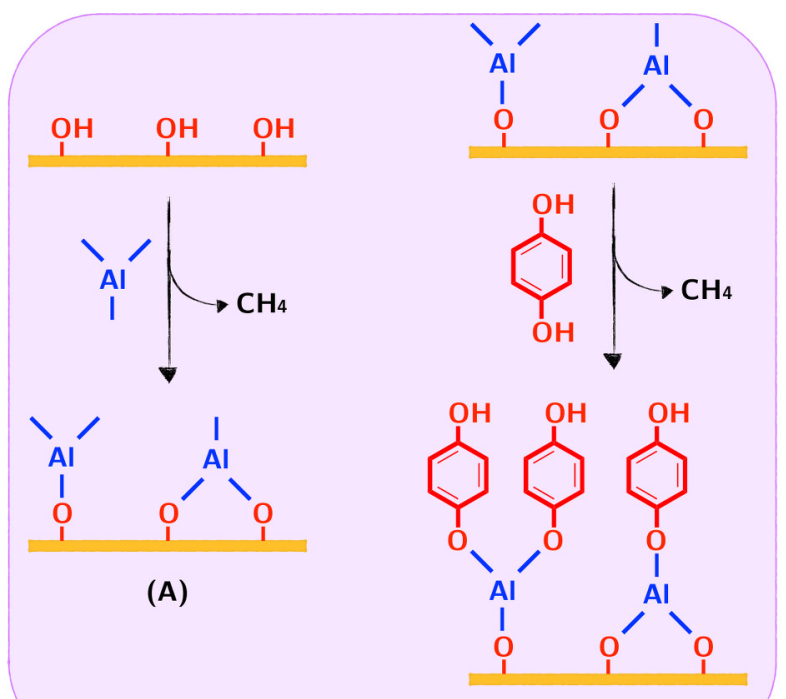

(B)
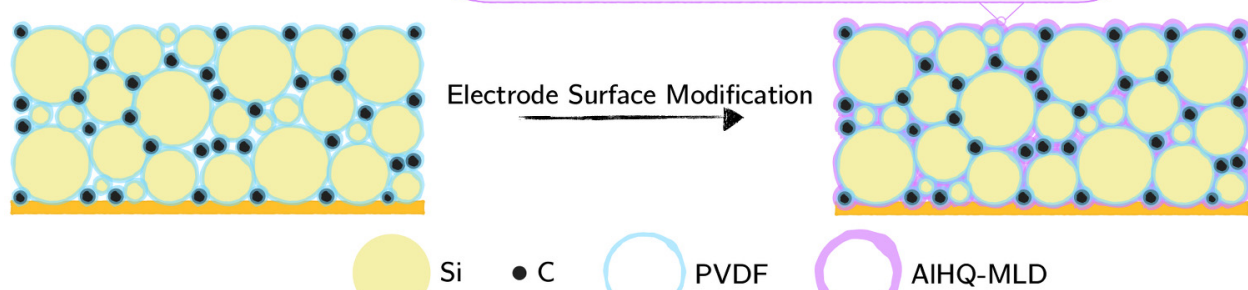

AIHQ-MLD

b as deposited AlHQ

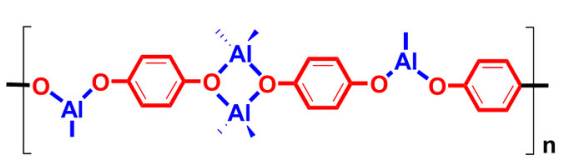<smiles>CCO[Al](C)Oc1ccc(O[Al]2ON(C)[Al](C)(C)O2)cc1</smiles><smiles>CCO[Al](C)Oc1ccc(O[Al]2ON(C)[Al](C)(C)O2)cc1</smiles>

( i )

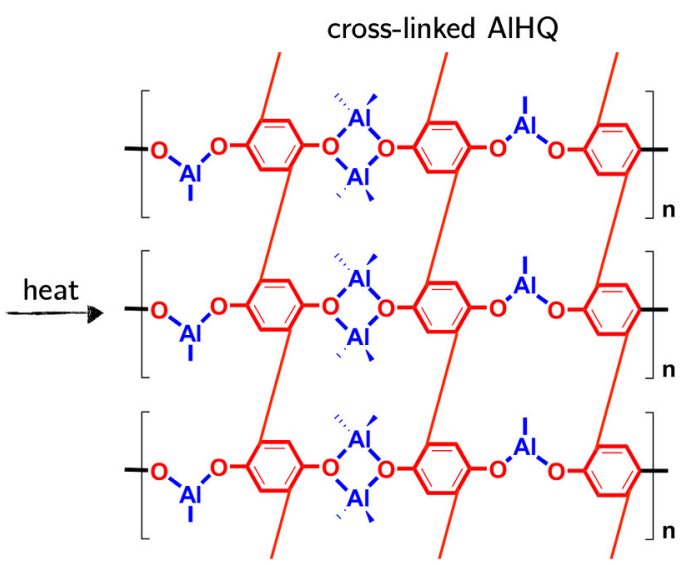

(ii )

Figure 1. (a) The controlled layered chemistry in MLD AlHQ coating, and the schematic of MLD coating for the laminated Si electrode. The AlHQ coating is based on sequential, selflimiting reactions of trimethylaluminum $\left(\mathrm{Al}\left(\mathrm{CH}_{3}\right)_{3}\right)$ and hydroquinone $\left(\mathrm{C}_{6} \mathrm{H}_{4}(\mathrm{OH})_{2}\right)$. The growth rate of this MLD reactions is $7.5 \AA$ per $\mathrm{AB}$ cycle at a substrate temperature of $150^{\circ} \mathrm{C}$. (b) Schematic of the crosslinking process of the AlHQ chains after post-deposition heat treatments. Dehydrogenation occurs during the post-annealing process, which induces a longitudinal crosslinking reaction of the aluminum- dioxybenzene chains. The 3-D crosslinking structure enhances the conductivity and stability, leading to improved electrochemical performance. 


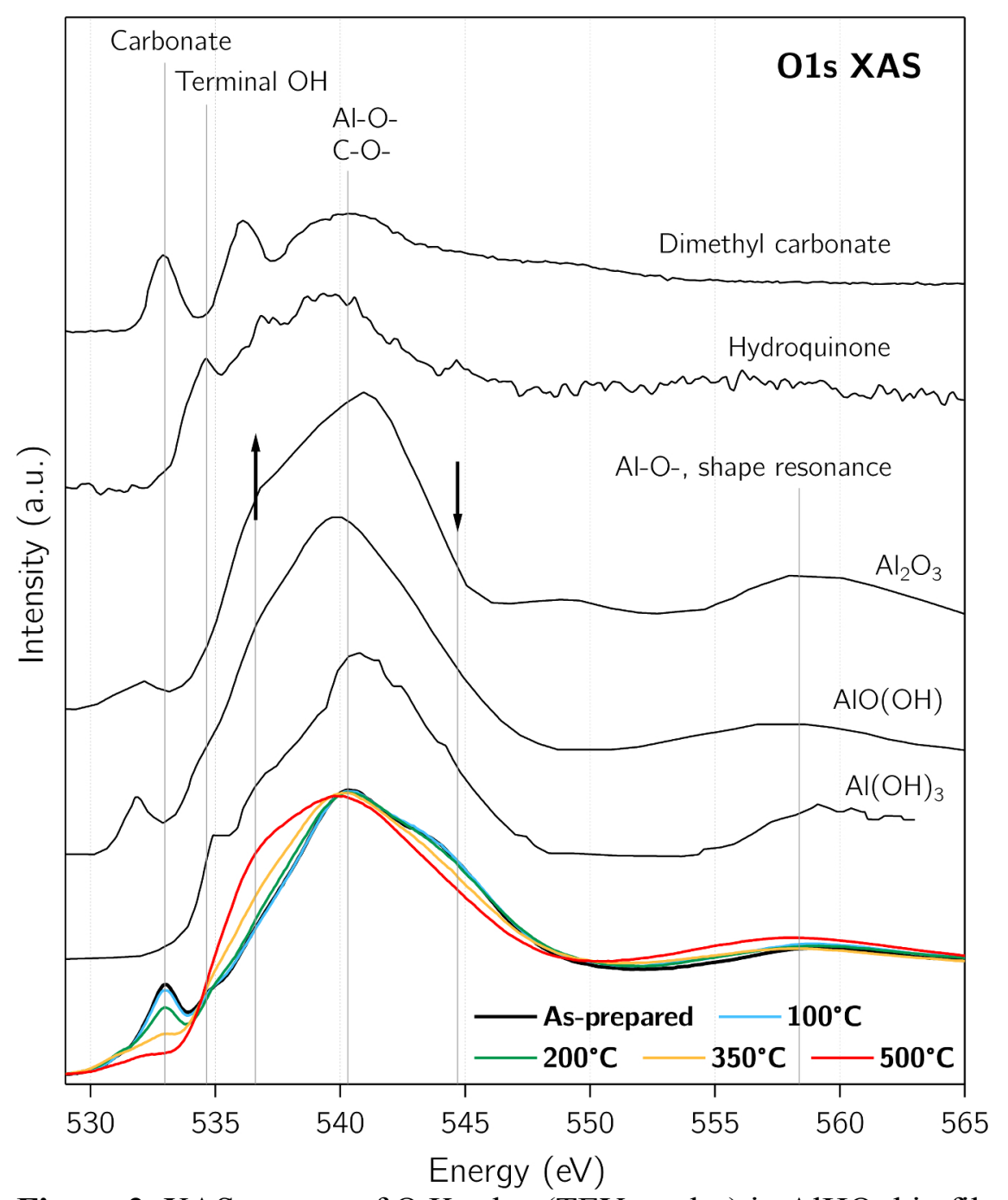

Figure 2. XAS spectra of O K-edge (TEY modes) in AlHQ thin films treated at 25, 100, 200, 350, and $500{ }^{\circ} \mathrm{C}$ under Ar environment. The reference spectra (Al (oxy)hydroxides) reproduced from [34-36] and gas-phase electron energy-loss spectroscopy (EELS) data from Hitchcock et al. $[39,40]$ are shown to aid the interpretation of the chemistry evolution with increasing temperature. 

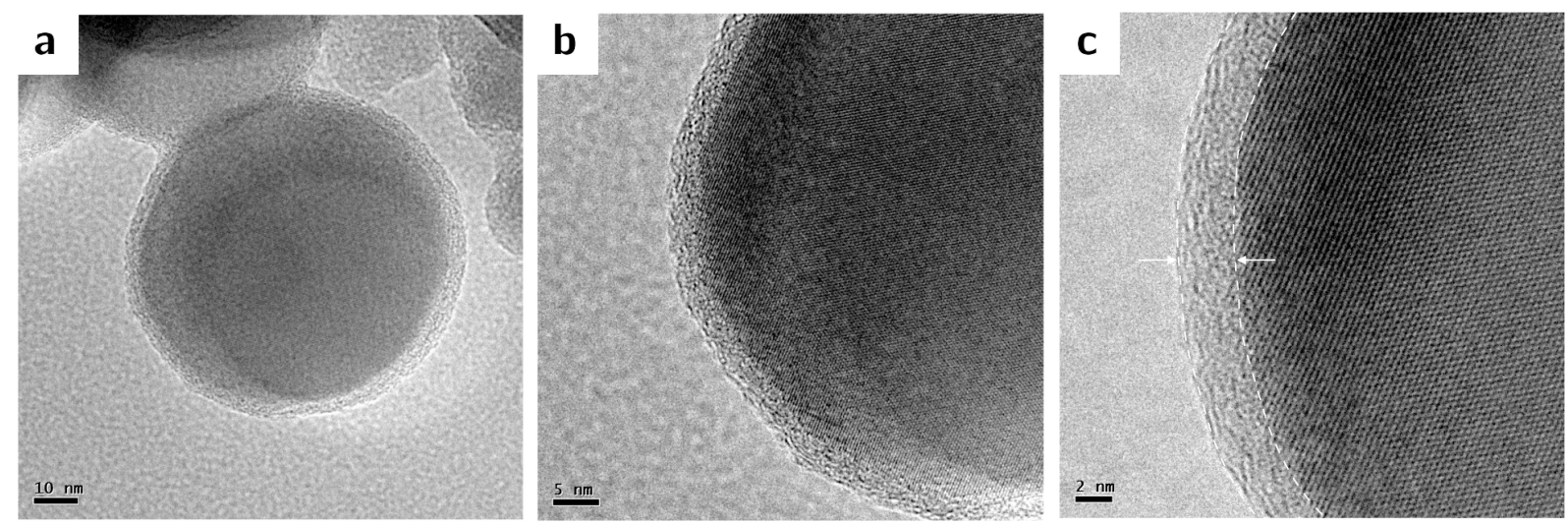

Figure 3. (a-c) TEM images of the coated Si particles in the coated Si electrode. The coating has been annealed under Ar at $200^{\circ} \mathrm{C}$. Images show a $\sim 3-\mathrm{nm}$ conformal thin coating of AlHQ on the nano-Si particles. The coating provides an intimately linked conductive network that connects nano-Si particles throughout the electrode. (c) High-resolution micrograph delineating the Ar-treated AlHQ coating adhered to the highly ordered crystalline nano-Si particle (white arrows and dotted lines). 

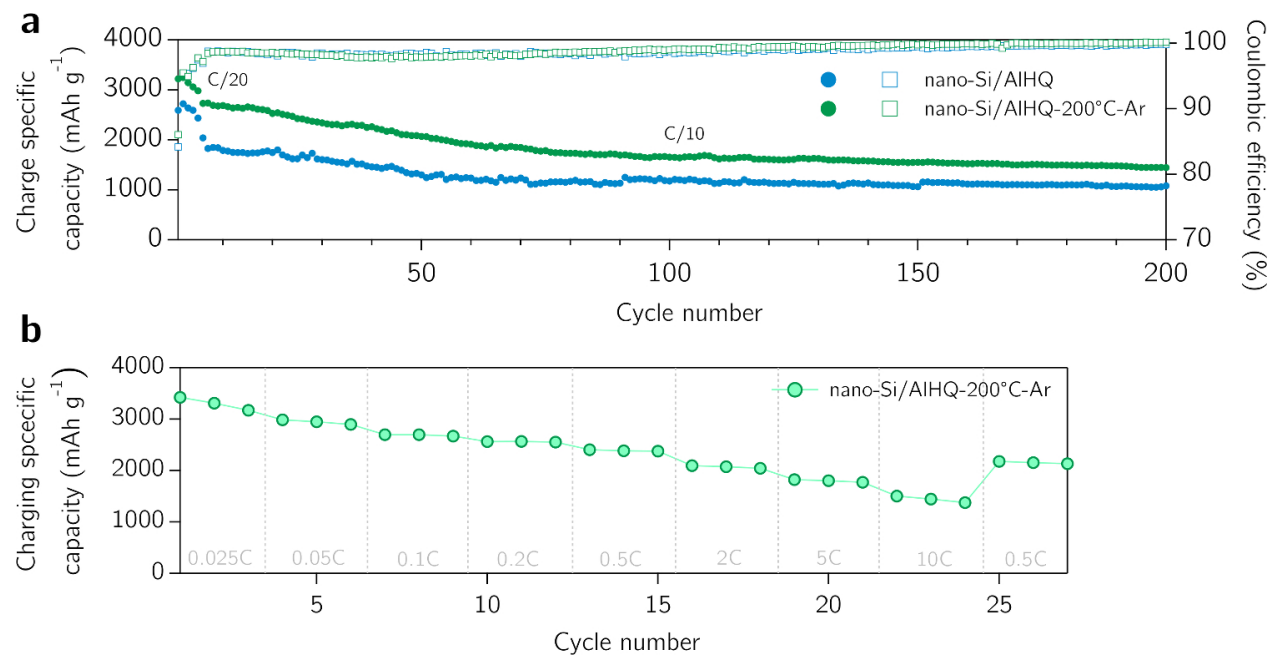

Figure 4. (a) Cyclic capacity and CE of a Si anode coated with as-deposit AlHQ (blue symbols) compared to the cyclic capacity and CE of a Si anode coated with Ar-treated AlHQ (green symbols). At cycle 200, the Ar-treated Si anode exhibits a specific charge capacity of nearly $1500 \mathrm{mAh} \mathrm{g}^{-1}$ and CEs in excess of 99\%, whereas the as-deposit coating enables the $\mathrm{Si}$ anode to achieve a stable capacity of about $1000 \mathrm{mAh} \mathrm{g}^{-1}$. (b) A rate test demonstrates that the Ar-treated electrode can achieve an average specific charge capacity of $1798 \mathrm{mAh} \mathrm{g}^{-1}$ at a rate of $5 \mathrm{C}$ and specific charge capacities of about $1500 \mathrm{mAh} \mathrm{g}^{-1}$ at a rate of $10 \mathrm{C}$. All the capacities were normalized based on total Si-active material in each electrode. 
Table 1. Nanoindentation results of AlHQ thin films treated at various temperatures in air revealing the highest $H / E^{*}$ for the AlHQ coating heat-treated at $150{ }^{\circ} \mathrm{C}$. The longitudinal crosslinking reaction of the aluminum-dioxybenzene chains enhances the mechanical properties, leading in a more elastic than plastic deformation under contact.

\begin{tabular}{cccc}
$\begin{array}{c}\text { AlHQ } \\
\begin{array}{c}\text { Temperature } \\
\text { Treatment } \\
{\left[{ }^{\circ} \mathrm{C} \text { in air }\right]}\end{array}\end{array}$ & $\begin{array}{c}\text { Elastic } \\
\text { Modulus } \\
{\left[\mathrm{E}^{*}, \mathrm{GPa}\right]}\end{array}$ & $\begin{array}{c}\text { Hardness } \\
{[\mathrm{H}, \mathrm{GPa}]}\end{array}$ & ${\mathrm{H} / \mathrm{E}^{*}}^{*}$ \\
\hline 25 & 29.2 & 1.24 & 0.0425 \\
$\mathbf{1 5 0}$ & $\mathbf{3 4 . 9}$ & $\mathbf{1 . 8 2}$ & $\mathbf{0 . 0 5 2 2}$ \\
200 & 60.2 & 2.50 & 0.0415 \\
\hline
\end{tabular}


Graphical Abstract:
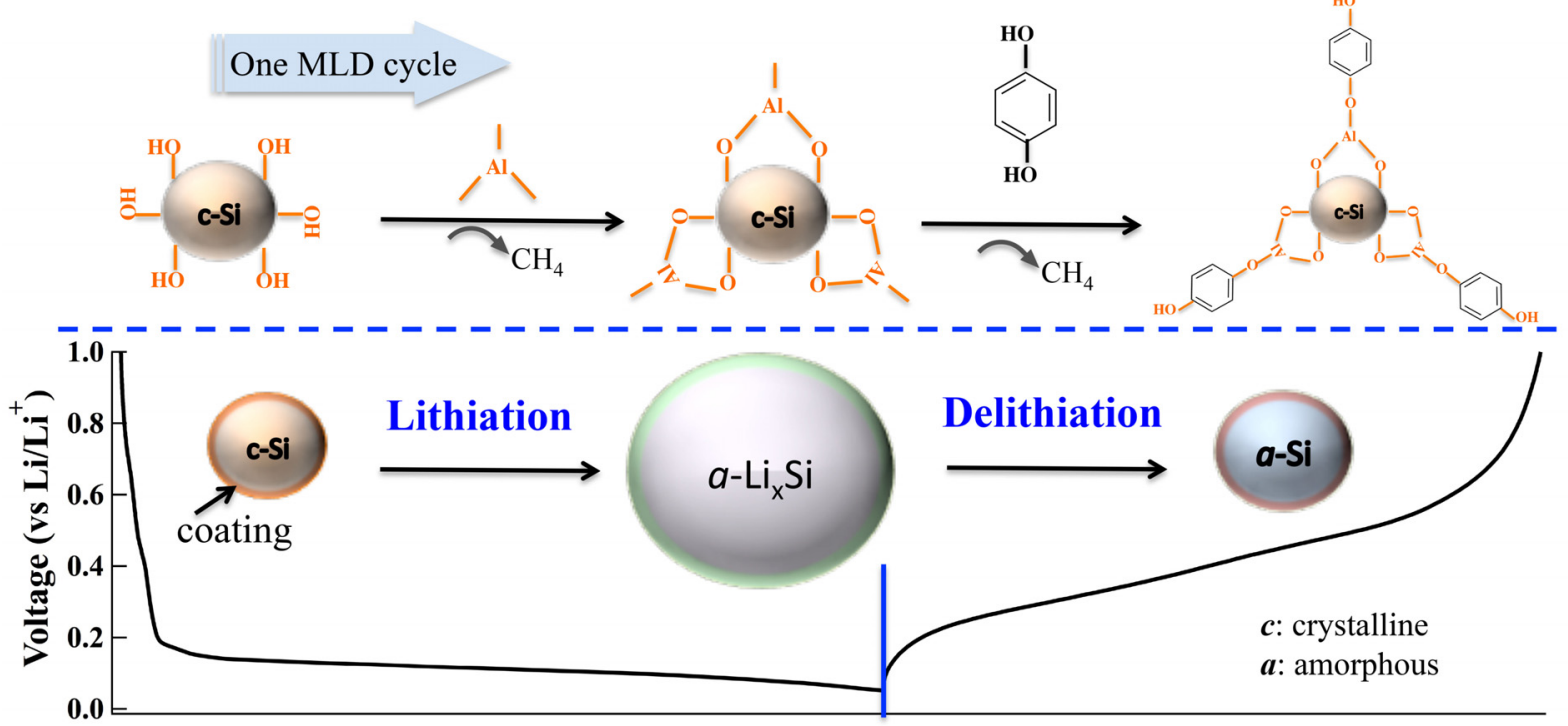